\title{
Standardization of Exercise Tests in Asthmatic Children
}

\author{
M. SILVERMAN and SANDRA D. ANDERSON \\ with the assistance of Tina Andrea \\ From the Department of Paediatrics, Institute of Diseases of the Chest, London
}

\begin{abstract}
Silverman, M., and Anderson, S. D. (1972). Archives of Disease in Childhood, 47, 882. Standardization of exercise tests in asthmatic children. Asthmatic children, known to be susceptible to exercise-induced bronchoconstriction, exercised by running or walking on a treadmill. Changes in airways obstruction were estimated by measurement of peak expiratory flow rate before, during, and after exercise. Post exercise bronchoconstriction reached a maximum when the duration of exercise was 6 to 8 minutes and when the gradient of the treadmill was 10 to $15 \%$; exercise for longer periods or at steeper gradients produced no significant increase in bronchoconstriction. Bronchoconstriction was much greater after running than after walking at the same oxygen consumption in 4 out of the 5 subjects tested.

The reproducibility of bronchoconstriction was good in individual patients when tests performed within one day or within one week were compared. Reproducibility diminished as the interval between tests increased to one month or one year. When tests were repeated at 2-hourly intervals throughout the day, no significant diminution in exercise-induced bronchoconstriction was noted. Variations in pre-exercise peak expiratory flow rate had no significant effect on exercise-induced bronchoconstriction in individual subjects.

The range of response of normal children to treadmill exercise is defined and the value of the test in discriminating between asthmatic and other children is shown.

If several tests are to be carried out by an individual patient, they should be performed on separate days at the same time of day and should be completed within one week. This will allow accurate comparisons to be made between tests in, for example, the assessment of the effect of different drugs in an individual patient.
\end{abstract}

Exercise tests have become accepted practice in the management of wheezy children since the work of Jones and his colleagues (Jones, Buston, and Wharton, 1962; Jones, Wharton, and Buston, 1963; Jones, 1966). The high incidence of exerciseinduced bronchoconstriction (EIB) in asthmatic children (Jones, 1966) and its previously reported absence in normal children and children with other chest diseases (Heimlich, Strick, and Busser, 1966) have allowed a high degree of discrimination between asthmatics and normal subjects. A classification of childhood asthma has been made by Jones (1966) on the basis of bronchial lability determined by changes in the forced expiratory volume in one second $\left(F V_{1}\right)$ occurring during and after exercise. Recently it has been suggested that exercise tests may be used to evaluate the efficacy of drugs used in the management of individual patients (Connolly

Received 3 May 1972. and Godfrey, 1970; Blackhall and Jones, 1970) and some evidence has been obtained to justify this point (M. Silverman, N. Connolly, and S. Godfrey, personal observations).

However, in spite of the now widespread use of exercise tests in the assessment of drug action in asthmatic children (Jones et al., 1963; Sly et al., 1967; Blackhall and Jones, 1970; Connolly and Godfrey, 1970), there appears to be relatively little 'control' data in the published reports. Jones (1966) stated that bicycle ergometer exercise gave variable results and that 8 minutes of corridor running was the most suitable provocation test. The reproducibility of EIB as measured by the 'lability index' was calculated by Jones (1966) from paired data in 12 patients and expressed as the coefficient of variation, with a value of $20 \%$. Bronchial lability was also measured in a group of normal children.

There are still disagreements concerning the 
variables involved in exercise testing. Bicycle ergometer exercise was thought by some to be as useful and effective as treadmill exercise (Pierson, Bierman, and Stamm, 1969; Katz and Whipp, 1969; Katz, 1970; Katz et al., 1971) and to give 'reproducible results', though our own calculations on the published data of Pierson et al. (1969) showed a high degree of variability. Moerover, it has recently been clearly shown under carefully controlled conditions that EIB is almost always greater after treadmill exercise than after bicycle ergometer exercise (Anderson, Connolly, and Godfrey, 1971). In other large-scale studies of asthmatic children, treadmill walking rather than running has been used as the provoking stimulus (Sly et al., 1967; Sly, 1970) and has failed to produce the degree of EIB which our own observations and the results of Jones (1966) would lead us to expect. It appears that running is a more potent stimulus than is walking and that this variable has not previously been investigated.

Again, while it has been shown that in 2 adult asthmatics successive exercise tests performed throughout a day tended to provoke diminishing degrees of EIB (McNeill et al., 1966), studies involving arterial cannulation of asthmatic children have recently been reported in which the possible effects of repeated exercise were ignored (Katz et al., 1971), perhaps leading to false conclusions about the nature of EIB. The effect of frequently repeated exercise during a single day on EIB in childhood has not been reported.

It was decided to standardize a simple exercise test for use in childhood asthma; to relate the response to exercise to the clinical condition of individual patients; to assess the reproducibility of the exercise test in asthmatic children over periods of time of from 2 hours to 1 year; and to evaluate the response of normal children.

\section{Subjects and Methods}

The asthmatic children who prrformed most of the tests were aged 5 to 16 years and were attending the Brompton Paediatric Clinic. These children all had asthma as defined by Scadding (1966), and symptoms had been severe enough to cause the loss of at least $15 \%$ of schooling in the year before being seen in our laboratory. All had perennial attacks of asthma, at least one positive immediate reaction to prick testing, and all had been shown to develop EIB. No child performed any test if a drug had been taken within the previous 8 hours.

The group of 97 unselected asthmatic children in whom the incidence of EIB was studied came from the same clinic and had asthma judged by the same criteria. The severity of their disease was variable.
The healthy controls were boys and girls aged between 7 and 15 years. They were all normal on physical examination and none had a history of cardiorespiratory disease or of any recent illness.

Exercise tests comprised nonstop running or walking on a treadmill (Quinton) at gradients of 0 to $20 \%$ and speeds of 2.5 to 3.5 m.p.h. Except where stated, each individual performed only one test on any day. Changes in airways obstruction were assessed using a Wright peak flow meter (Airmed) and measurements of peak expiratory flow rate (PEFR) were made before, during, and after exercise. Heart rate was measured during exercise by means of a 3-lead electrocardiograph or by counting the pulse-rate at the wrist at the end of exercise. At the end of each test 2 puffs of salbutamol aerosol were administered to each child, followed by a further minute of exercise. This maneouvre, designed to produce bronchodilatation, is an essential step in the calculation of an index of lability similar to that described by Jones (1966) who, however, measured $\mathrm{FEV}_{1}$ and gave isoprenaline before a period of 1 to 2 minutes exercise.

Tests performed by asthmatic children. The following studies were carried out on these children.

Effect of work load on EIB. 9 children ran on the treadmill for 6 minutes, each child at a constant speed of between 2.7 and 3.5 m.p.h. Each child performed 5 tests in random order on different days at varying gradients between 0 and $20 \%$.

Effect of duration of exercise on EIB. In a series of running tests performed by each of 10 children on a treadmill, the duration of exercise was varied between 1 and 16 minutes. The speed and gradient of the treadmill were constant for each child.

Comparison of running with walking. During these studies measurements were made of heart rate, minute ventilation, and oxygen consumption. 5 subjects, one of whom was a man aged 28 , walked or ran on the treadmill for 6 minutes (or 8 minutes in the case of the adult) on two separate occasions, the order of the tests being randomized. During exercise, subjects breathed through a low resistance, low dead-space $(53 \mathrm{ml})$ one-way valve suspended by rubber bands so that it was mobile. Expired gas was flushed through a large Tissot spirometer in which a measured volume of gas was collected during the last minute of exercise. The mixed expired gas was analysed for $\mathrm{CO}_{2}$ (URAS4) and for $\mathrm{O}_{2}$ (Servomex) in analysers which were calibrated after each test with accurately known gas mixtures previously analysed by the micro-Scholander method. PEFR was measured in these tests by means of a pneumotachograph (Fleisch) mounted on the valve assembly. All recordings were made using an ink-jet chart recorder (Mingograf 81).

For the first test on any subject, the treadmill was set to produce a heart rate of greater than 160 beats per minute. During the second test, the treadmill was set to produce the same oxygen consumption as during 
the first test, using the adult data of Givoni and Goldman (1971) to predict the appropriate treadmill settings. Minute ventilation, oxygen consumption, and heart rate were calculated for both walking and running studies in each individual and compared with the degree of bronchoconstriction provoked by the exercise.

Reproducibility studies. 8 asthmatic children spent one whole day in the laboratory. Each performed a series of running tests at 2-hourly intervals, speed, gradient, and duration being constant for each individual. No drug was administered between successive tests.

Other children performed running tests, each at a constant speed, slope, and duration at intervals of a few days (less than one week), one month ( \pm one week), or one year ( \pm one month). Analysis of variance was used to determine the 'within-patient' coefficient of variation of the indices of bronchial lability over these intervals of time. (Coefficient of variation $=\mathrm{SD}$ / mean $\times 100 \%$.)

Tests performed by normal children. 19 normal schoolchildren performed one 6-minute running test on the treadmill which was set at $10 \%$ slope and 3.0 to 3.5 m.p.h. Measurements of PEFR were made at rest, during, and after exercise.

\section{Calculations}

The following indices were calculated; predicted values for spirometry and PEFR were taken from Godfrey, Kamburoff, and Nairn (1970):

(i) Initial PEFR =

$$
\frac{\text { Pre-exercise PEFR }}{\text { Predicted PEFR }} \times 100 \%
$$

(ii) Fall in PEFR =

$$
\frac{\text { Pre-exercise PEFR-Lowest PEFR }}{\text { Pre-exercise PEFR }} \times 100 \%
$$

(iii) Lability Index $=$

Highest overall PEFR-Lowest overall PEFR

$$
\text { Predicted normal PEFR at rest }
$$

All statistical comparisons were made using paired ' $t$ ' tests and the level of significance (2-tail) was taken as $\mathbf{P}<0.05$.

\section{Results}

Asthmatic subjects. The following results were shown in asthmatics.

Effect of workload on EIB. Increasing the workload by changing the gradient of the treadmill caused an increase in the amount of bronchoconstriction as measured by the fall in PEFR as well as a rise in bronchial lability as measured by the lability index (Fig. 1 and 2). Maximum values were attained at gradients of 15 to $20 \%$. There were no significant differences between the values obtained at the $10 \%, 15 \%$, or $20 \%$ gradients, but

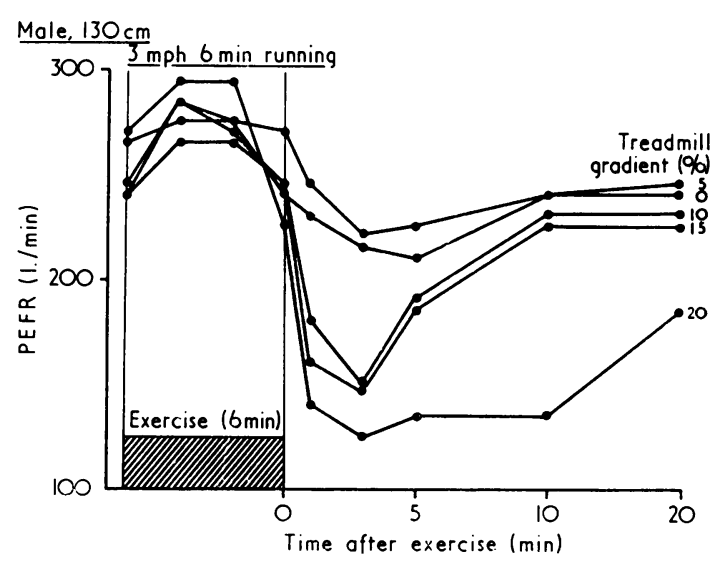

FIG. 1.-Series of running tests performed by a single subject, each test at a different treadmill gradient.

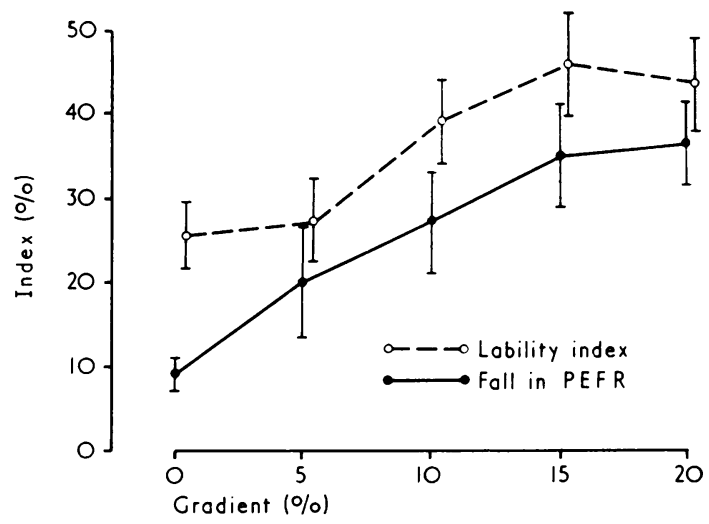

FIG. 2.-Relation between two indices of exercise-induced bronchoconstriction and treadmill gradient during a series of running tests. Mean values $( \pm 1 S E)$ are given for the 9 subjects who each performed the complete series.

these were significantly higher than the values obtained at the $0 \%$ and $5 \%$ gradients. Using the data for maximum oxygen uptake in children of Astrand (1952) and our own (unpublished) data relating oxygen consumption to treadmill speed and slope for children, we have constructed a table in order to predict the relative work rates of children exercising at the workloads used in this study (Table I). At 10 to $15 \%$ gradient, the children were exercising at between 60 to $85 \%$ of their predicted maximum oxygen consumption.

Effect of duration of exercise on EIB. Maximum values of the indices of EIB were obtained after exercise tests of 6 to 8 minutes' duration 
TABLE I

Oxygen Consumption as Percentage of Predicted Maximum Oxygen Consumption During Treadmill Running (\%)

\begin{tabular}{|c|c|c|c|}
\hline \multirow{2}{*}{ Speed (m.p.h.) } & \multicolumn{3}{|c|}{ Gradient } \\
\hline & $10 \%$ & $15 \%$ & $20 \%$ \\
\hline $\begin{array}{l}2 \cdot 5 \\
3 \cdot 0 \\
3 \cdot 5\end{array}$ & $\begin{array}{l}53-64 \\
60-73 \\
64-76\end{array}$ & $\begin{array}{l}61-73 \\
67-80 \\
71-85\end{array}$ & $\begin{array}{l}68-81 \\
74-89 \\
79-94\end{array}$ \\
\hline
\end{tabular}

(Fig. 3 and 4). Values obtained after exercise tests of 1,2 , and 4 minutes' duration were significantly less. After 1 minute of exercise, 2 of the 10 subjects had no net fall in PEFR, only bronchodilatation occurred. One of these subjects also demonstrated the same effect after an exercise test of 2 minutes' duration. Out of 8 subjects who attempted the 16-minute exercise test, 5 developed bronchoconstriction and one gave up after 10 minutes though not wheezy. Two other subjects developed little EIB after completing 16 minutes of running, though on other days they developed marked EIB (falls in PEFR of $32 \%$ and $38 \%$ ) after only 8 minutes of exercise.

Comparison of running with walking. For the 5 subjects studied there was no significant difference between the walking and running tests with respect to oxygen consumption, minute ventilation, heart rate, or end-tidal $\mathrm{PCO}_{2}$. EIB was generally greater after running than after walking (Table II). In 3 subjects running provoked severe EIB when

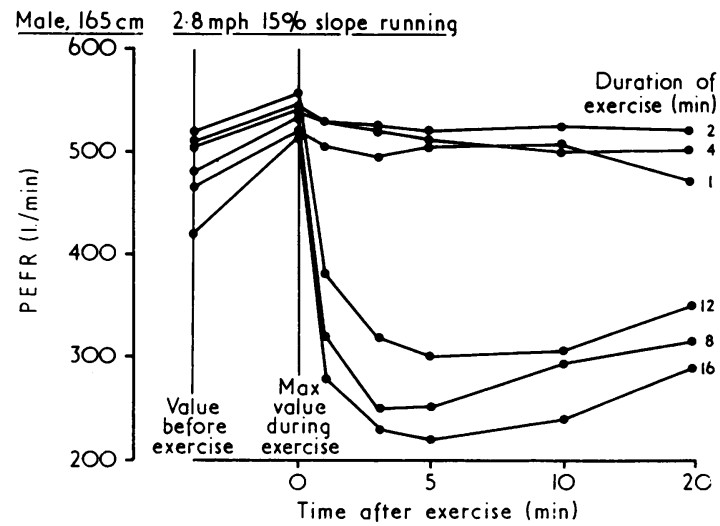

FIG. 3.-Series of running tests performed by a single suhject at a single speed and gradient, the duration of exercise being different in each test.

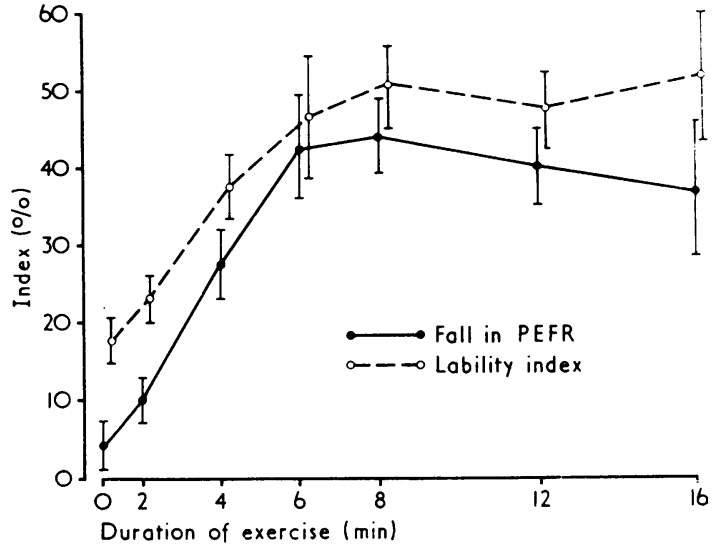

FIG. 4.-Relation between two indices of exercise-induced bronchoconstriction and duration of exercise during a series of treadmill running tests. Mean values ( $\pm 1 S E$ ) are given for the 10 subjects who each performed the series.

the fall in PEFR after walking was within normal limits (i.e. less than 10\%).

Reproducibility studies. For individual patients, the EIB measured as fall in PEFR or the lability index was less reproducible as the interval between successive tests increased (Table III). The coefficients of variation were lowest when test was repeated at intervals of less than one week, and were highest when a one-month or a one-year interval separated tests. Analysis of the results of studies repeated at 2-hourly intervals during a single day (Fig. 5) showed that, though there were diurnal variations in lability, there was no significant change in resting PEFR, lability index, or the fall in PEFR after exercise. The coefficient of variation of these parameters was greater in the 2-hourly test series than in the daily test series.

Normal children. The 19 normal schoolchildren responded to exercise with a mean maximum rise in PEFR during exercise of $7.5 \%$ and a mean maximum fall after exercise of $2 \cdot 4 \%$ with an upper limit of normal (mean +2 SD) of $10 \%$. The mean value of lability index was $12 \cdot 4 \%$ with an upper limit of normal of $22 \%$. The mean heart rate of these children after 6 minutes of running at 3.5 m.p.h. up a $10 \%$ gradient was 172 .

\section{Discussion}

The present study suggests that the treadmill exercise test which will provoke the maximum 
TABLE II

Effect of Walking and Running on Exercise-induced Bronchoconstriction

\begin{tabular}{|c|c|c|c|c|c|c|c|c|c|c|c|c|c|c|c|}
\hline \multirow{3}{*}{ Subject } & \multirow{3}{*}{$\begin{array}{l}\text { Age } \\
\text { (yr) } \\
\text { and } \\
\text { Sex }\end{array}$} & \multicolumn{4}{|c|}{ Treadmill Settings } & \multirow{2}{*}{\multicolumn{2}{|c|}{$\begin{array}{c}\text { Oxygen } \\
\text { Consumption } \\
(\mathrm{ml} / \mathrm{min})\end{array}$}} & \multirow{2}{*}{\multicolumn{2}{|c|}{$\begin{array}{c}\text { Minute } \\
\text { Ventilation } \\
(1 . / \mathrm{min})\end{array}$}} & \multirow{2}{*}{\multicolumn{2}{|c|}{$\begin{array}{l}\text { Heart Rate } \\
\text { (beats/min) }\end{array}$}} & \multirow{2}{*}{\multicolumn{2}{|c|}{$\begin{array}{c}\text { Fall in } \\
\text { PEFR } \\
(\%)\end{array}$}} & \multirow{2}{*}{\multicolumn{2}{|c|}{$\begin{array}{c}\text { Lability } \\
\text { Index } \\
(\%)\end{array}$}} \\
\hline & & \multicolumn{2}{|c|}{ W/alking } & \multicolumn{2}{|c|}{ Running } & & & & & & & & & & \\
\hline & & $\begin{array}{c}\text { Speed } \\
\text { (m.p.h.) }\end{array}$ & $\begin{array}{l}\text { Gradient } \\
(\%)\end{array}$ & $\begin{array}{c}\text { Speed } \\
\text { (m.p.h.) }\end{array}$ & $\begin{array}{l}\text { Gradient } \\
(\%)\end{array}$ & Walk & Run & Walk & Run & Walk & Run & Walk & Run & Walk & Run \\
\hline $\begin{array}{l}1 \\
2 \\
3 \\
4 \\
5\end{array}$ & $\begin{array}{rl}12 & M \\
11 & F \\
14 & F \\
7 & M \\
28 & M\end{array}$ & $\begin{array}{l}3 \cdot 0 \\
3 \cdot 5 \\
3 \cdot 0 \\
3 \cdot 5 \\
3 \cdot 0\end{array}$ & $\begin{array}{l}20 \\
15 \\
20 \\
12 \\
15\end{array}$ & $\begin{array}{l}3 \cdot 0 \\
3 \cdot 0 \\
2 \cdot 5 \\
3 \cdot 0 \\
3 \cdot 0\end{array}$ & $\begin{array}{l}15 \\
10 \\
10 \\
10 \\
10\end{array}$ & $\begin{array}{r}1145 \\
1060 \\
1034 \\
935 \\
2940\end{array}$ & $\begin{array}{r}1290 \\
1090 \\
1020 \\
838 \\
3040\end{array}$ & $\begin{array}{l}35 \\
33 \\
33 \\
30 \\
61\end{array}$ & $\begin{array}{l}42 \\
35 \\
28 \\
27 \\
65\end{array}$ & $\begin{array}{l}165 \\
165 \\
174 \\
174 \\
188\end{array}$ & $\begin{array}{l}177 \\
174 \\
171 \\
173 \\
189\end{array}$ & $\begin{array}{r}5 \cdot 5 \\
30 \cdot 0 \\
5 \cdot 0 \\
2 \cdot 0 \\
18 \cdot 5\end{array}$ & $\begin{array}{l}36 \cdot 0 \\
28 \cdot 5 \\
51 \cdot 0 \\
15 \cdot 2 \\
65 \cdot 5\end{array}$ & $\begin{array}{l}25 \\
38 \\
19 \\
33 \\
36\end{array}$ & $\begin{array}{l}35 \\
43 \\
60 \\
56 \\
65\end{array}$ \\
\hline $\begin{array}{l}\text { Mean } \\
\text { SEM }\end{array}$ & & & & & & $\begin{array}{r}1423 \\
381\end{array}$ & $\begin{array}{r}1456 \\
403\end{array}$ & $\begin{array}{c}38 \\
5 \cdot 7\end{array}$ & $\begin{array}{c}39 \\
7 \cdot 0\end{array}$ & $\begin{array}{c}173 \\
4 \cdot 2\end{array}$ & $\begin{array}{r}177 \\
3 \cdot 2\end{array}$ & $\begin{array}{r}12 \cdot 0 \\
5 \cdot 3\end{array}$ & $\begin{array}{r}39 \cdot 0 \\
8 \cdot 8\end{array}$ & $\begin{array}{c}30 \\
3 \cdot 6\end{array}$ & $\begin{array}{l}52 \\
5 \cdot 5\end{array}$ \\
\hline $\mathbf{P}$ & & & & & & & & $\mathrm{N}$ & & NS & & $\begin{array}{l}\mathbf{t}= \\
\mathbf{P}<\end{array}$ & .87 & $\begin{array}{l}\mathbf{t}= \\
\mathbf{P}<\end{array}$ & $\cdot 38$ \\
\hline
\end{tabular}

SEM = standard error of mean.

NS $=$ not significant $(P>0 \cdot 05)$.

TABLE III

Reproducibility (within-patients) of EIB over Various Time Intervals, Measured by Treadmill Running Tests

\begin{tabular}{|c|c|c|c|c|c|c|c|c|}
\hline \multirow{2}{*}{$\begin{array}{c}\text { Time } \\
\text { Interval }\end{array}$} & \multirow{2}{*}{$\begin{array}{c}\text { No. } \\
\text { of } \\
\text { Subiects }\end{array}$} & \multirow{2}{*}{$\begin{array}{l}\text { No. } \\
\text { of } \\
\text { Tests }\end{array}$} & \multicolumn{3}{|c|}{ Fall in PEFR (\%) } & \multicolumn{3}{|c|}{ Lability Index (Jones, 1966) (\%) } \\
\hline & & & $\begin{array}{l}\text { Mean } \\
\text { (group) }\end{array}$ & $\stackrel{\mathrm{SD}}{\text { (individual) }}$ & $\begin{array}{l}\text { Coefficient } \\
\text { of Variation } \\
\text { (individual) }\end{array}$ & $\begin{array}{c}\text { Mean } \\
\text { (group) }\end{array}$ & $\underset{\text { (individual) }}{\mathrm{SD}}$ & $\begin{array}{l}\text { Coefficient } \\
\text { of Variation } \\
\text { (individual) }\end{array}$ \\
\hline $\begin{array}{l}2 \text { hours } \\
\text { Within } 1 \text { week } \\
1 \text { month ( } \pm 1 \text { week) } \\
1 \text { year }( \pm 1 \text { month })\end{array}$ & $\begin{array}{r}8 \\
5 \\
40 \\
13\end{array}$ & $\begin{array}{l}30 \\
17 \\
96 \\
27\end{array}$ & $\begin{array}{l}46 \\
31 \\
30 \\
25\end{array}$ & $\begin{array}{r}14 \cdot 6 \\
6 \cdot 5 \\
15 \cdot 5 \\
13 \cdot 2\end{array}$ & $\begin{array}{l}31 \\
21 \\
53 \\
53\end{array}$ & $\begin{array}{l}51 \\
39 \\
38 \\
33\end{array}$ & $\begin{array}{r}12 \cdot 9 \\
5 \cdot 5 \\
13 \cdot 3 \\
9 \cdot 2\end{array}$ & $\begin{array}{l}25 \\
14 \\
35 \\
28\end{array}$ \\
\hline
\end{tabular}

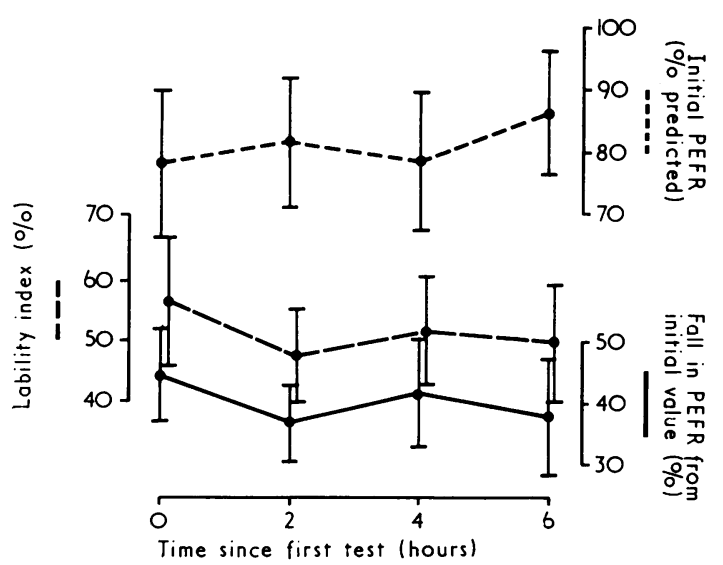

FIG. 5.-Mean values ( $\pm 1 S E$ ) of initial PEFR and of two indices of exercise-induced bronchoconstriction measured 4 times in a single day in 8 subjects. degree of bronchoconstriction in a susceptible patient consists of 6 to 8 minutes of running at about 3 m.p.h. up a slope of 10 to $15 \%$. At this level of work $(60-85 \%$ of maximum oxygen consumption) the heart rate may be expected to reach 170 to 175 beats/minute. If two tests are to be compared in one child, before and after administration of a drug, for instance, the random variation between tests will be less if the interval between them is less than one week and if tests are performed at the same time of day.

The fact that some subjects developed much more severe bronchoconstriction after running than walking may account for the poor results obtained by workers using a treadmill walking test. Sly (1970), using such a test, found significant EIB in only $39 \%$ of 116 asthmatic children. By contrast we have found that $73 \%$ of asthmatic children developed significant EIB after their first treadmill running test (Table IV), and Jones (1966), using 
corridor running tests, has stated that virtually all asthmatic children have abnormal lability indices. The present study has shown that even if the level of work being performed is high, walking may fail to provoke bronchoconstriction in sensitive subjects. The relative efficacy of different forms of exercise in provoking EIB has been shown previously. Swimming is a weak stimulus (Fitch and Morton, 1971; S. D. Anderson, personal observations), while bicycle ergometer exercise, treadmill exercise, and free-range running are increasingly potent (Anderson et al., 1971).

TABLE IV

Analysis of First Treadmill Running Test Performed by 97 Wheezy Children from Hospital Outpatient Clinic

Proportion of Children Outside Normal Range

\begin{tabular}{c|c|c}
\hline $\begin{array}{c}\text { Fall in PEFR } \\
>10 \%\end{array}$ & $\begin{array}{c}\text { Lability Index } \\
>22 \%\end{array}$ & $\begin{array}{c}\text { Lability Index 15\% } \\
\text { (Jones, 1966) }\end{array}$ \\
\hline $70 \%$ & $67 \%$ & $86 \%$ \\
\hline
\end{tabular}

Note: $75 \%$ of children had at least one abnormal value.

The relatively greater potency of free-range (or corridor) running may explain the difference in the frequency of EIB between the present study and that of Jones (1966). Another important factor in explaining this difference may be the variability of the test. Since the day-to-day variation of lability index in the present study was $14 \%$, it might be expected that after a second exercise test, a certain number of asthmatic children who initially had a normal response to exercise might have an abnormal degree of lability. Because our upper limit of lability index for normal subjects was $22 \%$, we have given a lower estimate of the proportion of asthmatics who develop EIB than did Jones (1966) whose upper limit of normal was $20 \%$. The difference is shown in Table IV. Small differences in techniques such as the use of $\mathrm{FEV}_{1}$ or PEFR to assess changes in airways obstruction have been shown to be of little importance. The coefficient of correlation between PEFR and FEV during and after exercise has been shown to be between 0.886 and 0.996 in 5 asthmatic subjects (personal observations).

The inferiority of bicycle ergometer exercise in provoking bronchoconstriction may be responsible for the small mean fall in $\mathrm{FEV}_{1}$ (30\%) which Pierson et al. (1969) found in their highly selected group of asthmatic children. Also, their claim that bicycle ergometer exercise is 'reproducible' is not borne out by an analysis of their data, summarized in Table V. Thus, we have not included any direct observations on bicycle ergometer exercise in the present study, feeling it to be unsuitable for this sort of test.

There appears to be a direct relation between the degree of bronchoconstriction produced and the severity or duration of the exercise up to a certain point when the plateau effect is seen (Fig. 2 and 4). Jones et al. (1962) suggested that a minimum amount of work ('threshold') must be exceeded before EIB will occur, and the present study suggests that during running this 'threshold' may be achieved by certain combinations of severity and duration of exercise.

After treadmill exercise of 1 and 2 minutes' duration, a mild degree of bronchoconstriction was observed in all but two of our subjects. These observations differ from those of Jones et al.

TABLE V

Reproducibility of Challenge Tests in Asthma

\begin{tabular}{|c|c|c|c|c|c|c|c|c|}
\hline \multirow{2}{*}{ Authors } & \multirow{2}{*}{ Challenge } & \multirow{2}{*}{ Parameter } & \multirow{2}{*}{$\begin{array}{c}\text { Interval } \\
\text { Between } \\
\text { Tests }\end{array}$} & \multirow{2}{*}{$\begin{array}{l}\text { No. of } \\
\text { Subjects }\end{array}$} & \multirow{2}{*}{$\begin{array}{l}\text { No. of } \\
\text { Tests }\end{array}$} & \multicolumn{3}{|c|}{ Change in Parameter (\%) } \\
\hline & & & & & & Mean & SD & $\begin{array}{l}\text { Coefficient } \\
\text { of Variation }\end{array}$ \\
\hline Jones (1966) & $\begin{array}{l}\text { Exercise (running; } \\
8 \mathrm{~min} \text { ) }\end{array}$ & $\begin{array}{l}\text { Lability Index } \\
\text { (based on FEV })\end{array}$ & $?$ & 12 & 24 & 56 & 11 & 20 \\
\hline Pierson et al. (1969) & $\begin{array}{l}\text { Exercise (bicycle ergo- } \\
\text { meter; } 5 \text { min) }\end{array}$ & $\mathrm{FEV}_{1}$ & $?$ & 15 & 65 & 30 & 37 & 54 \\
\hline Poppius et al. (1970) & $\begin{array}{l}\text { Exercise (bicycle ergo- } \\
\text { meter; min) }\end{array}$ & PEFR & $1-3 d y$ & 28 & 56 & 18 & 73 & 406 \\
\hline $\begin{array}{l}\text { Engstrom and } \\
\text { Vejmolova (1970) }\end{array}$ & $\begin{array}{l}\text { Bronchial challenge } \\
\text { antigen }\end{array}$ & Raw $^{\star}$ & $2 \mathrm{dy}$ & 12 & 34 & 322 & 153 & 48 \\
\hline $\begin{array}{l}\text { Cade and Pain (1971a) } \\
\text { Parker, Bilbo, and } \\
\text { Read (1965) }\end{array}$ & $\begin{array}{l}\text { Methylcholine aerosol } \\
\text { Methylcholine }\end{array}$ & $\begin{array}{l}\mathrm{FEV}_{1} \\
\mathrm{FEV}_{1}\end{array}$ & $\begin{array}{c}1 \text { wk } \\
\text { ? }\end{array}$ & $\begin{array}{r}5 \\
11\end{array}$ & $\begin{array}{l}21 \\
22\end{array}$ & $\begin{array}{l}31 \\
28\end{array}$ & $\begin{array}{l}15 \\
14\end{array}$ & $\begin{array}{l}49 \\
50\end{array}$ \\
\hline
\end{tabular}

^Airways resistance measured in a whole body plethysmograph. 
(1962) who showed only bronchodilatation after maximum exercise of this duration in a corridor. The difference remains unexplained.

The treadmill test appears to be of value in discriminating between asthmatic children and normal subjects, though because of the variability of the test, after a single test some $27 \%$ of asthmatics may not manifest abnormal lability. The observation by Heimlich et al. (1966) that patients with cystic fibrosis have a normal degree of bronchial lability has recently been refuted by Day and Mearns (1973). They found that 27 out of 52 children with cystic fibrosis had either an abnormal lability index or an abnormally great fall in PEFR after exercise, and hence an abnormal lability index cannot now be considered pathognomonic of asthma. There appears to be a spectrum of bronchial lability in response to exercise in the population, the lability of mild asthmatics and patients with cystic fibrosis falling between that of normal subjects and of highly labile asthmatics. Such a spectrum has been shown previously in response to exercise tests (König, Godfrey, and Abrahamov, 1972) and methylcholine inhalations (Cade and Pain, 1971a) and by clinical observations (Williams and McNicol, 1969).

We were unable to confirm the clinical impression that bronchial lability varied systematically with variations in the initial PEFR in individual patients (Fig. 6). Using other forms of 'bronchial challenge', Cade and Pain (1971b) with methylcholine inhalations, Sly (1970) using a treadmill walking test, and Pierson et al. (1969), during bicycle ergometer studies, also found no relation between initial spirometry and the response to challenge. Jones and Jones (1966) and Blackhall (1970) showed that EIB varied little in young ex-asthmatic subjects over several years. We have confirmed their observations, showing that the mean fall in PEFR in the group of subjects who performed 2 tests with an interval of one year, hardly altered $(24.4 \%$ to $25.6 \%$ ) and the lability index was also constant $(31.9 \%$ to $34 \cdot 4 \%)$. This observation contrasts with the improvement in clinical condition in a group of asthmatic children, which might be expected in the course of one year (Williams and McNicol, 1969) and again suggests that bronchial lability is a persistent feature of both asthmatic and ex-asthmatic patients, and that it is not closely related to the clinical condition or to the degree of airways obstruction in individual patients.

The coefficient of variation $(21 \%)$ of the fall in PEFR (\%) in daily exercise tests compares favourably with the variability of changes in airways resistance in other kinds of 'challenge tests' in

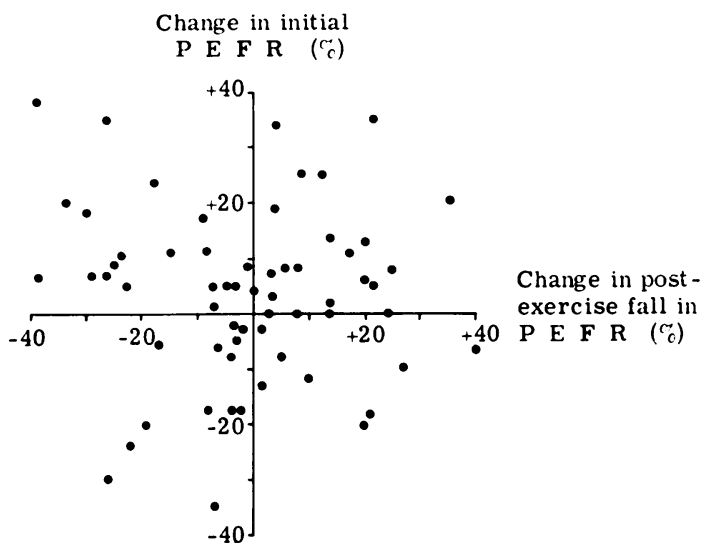

FIG. 6.-Scatter diagram to show that in a group of asthmatic children who each performed two exercise tests with an interval of one month, there was no correlation between change in the initial peak expiratory flow rate before exercise (vertical axis) and the change in the degree of exercise-induced bronchoconstriction which occurred (horizontal axis). The degree of exercise-induced bronchoconstriction was measured by the fall in PEFR after exercise (see text).

asthma (Table V). Comparison with the other studies shows the reproducibility of the simple treadmill running test to be good. Exercise tests have the added advantages that they can provoke attacks of asthma without the administration of foreign substances and that such attacks reproduce one of the major symptoms of childhood asthma.

McNeill et al. (1966) illustrated a progressive decrease in the severity of EIB in one subject who performed 6 exercise tests within 5 hours. However, in the present study, though there were diurnal variations in the fall in PEFR, in none of our subjects was there a progressive change in the severity of EIB in the course of 4 tests performed within 6 hours. It is unlikely that these diurnal variations could be related to the previous day's drug therapy, since maximum lability was demonstrated by the first test of the day (Fig. 5). The tests were performed at the following times; first test at 9-10 a.m., second at 11-12 a.m., third at 1-2 p.m., and fourth at 3-4 p.m., and hence the variations in lability could have been related to meal times. Because of these diurnal variations the coefficients of variation of the indices of EIB were greater for the 2-hourly tests than for tests performed at daily intervals.

From the present study, it thus appears practical and justifiable to compare 2 tests performed during one day in an individual patient, provided that the 
variations illustrated in Fig. 5 are taken into account. This means that a child attending a clinic could have a diagnostic or control exercise test in the morning followed by a second test in the afternoon to assess efficacy of a drug in preventing EIB. Ideally, however, successive tests should be performed at the same time of day, on separate days within one week. As has been suggested previously (Connolly and Godfrey, 1970; Blackhall and Jones, 1970), the laboratory assessment of drug action in this way may be expected to correlate well with the longterm clinical response to the drug, and a validation of these suggestions has recently been obtained. It has been shown in asthmatic children taking part in a long-term controlled trial of disodium cromoglycate (Silverman, et al., 1972) that the efficacy of the drug in preventing EIB correlated well with the long-term clinical response. The full clinical implications of this sort of exercise test have yet to be explored.

We are grateful for the guidance and encouragement of Dr. Simon Godfrey. The authors were given financial support by Fisons Pharmaceuticals Limited.

\section{REFERENCES}

Anderson, S. D., Connolly, N. M., and Godfrey, S. (1971). Comparison of bronchoconstriction induced by cycling and running. Thorax, 26, 396.

Astrand, P-O. (1952). Experimental Studies of Physical Working Capacity in Relation to Sex and Age, p. 104. Munksgaard, Copenhagen.

Blackhall, M. I. (1970). Ventilatory function in subjects with childhood asthma who have become symptom free. Archives of Disease in Childhood, 45, 363.

Blackhall, M. I., and Jones, R. S. (1970). Effect of intal on postexercise broncho-constriction in asthma. In Disodium Cromoglycate in Allergic Airways Disease, p. 63. Ed. by J. Pepys and A. W. Frankland. Butterworth, London.

Cade, J. F., and Pain, M. C. F. (1971a). Role of bronchial reacticity in aetiology of asthma. Lancet, $2,186$.

Cade, J. F., and Pain, M. C. F. (1971b). Bronchial reactivity. Its measurement and clinical significance. Australia and New Zealand fournal of Medicine, 1, 22.

Connolly, N., and Godfrey, S. (1970). Assement of the child with asthma. Fournal of Asthma Research, 8, 31.

Day, G., and Mearns, M. B. (1973). Bronchial lability in cystic fibrosis. Archives of Disease in Childhood. (In the press.)

Engstrom, I., and Vejmolova, J. (1970). The effect of disodium cromoglycate on allergen challenge in children with bronchial asthma. Acta Allergologica, 25, 382.
Fitch, K. D., and Morton, A. R. (1971). Specificity of exercise in exercise-induced asthma. British Medical fournal, 4, 577.

Givoni, B., and Goldman, R. F. (1971). Predicting metabolic energy cost. Fournal of Applied Physiology, 30, 429.

Godfrey, S., Kamburoff, P. L., and Nairn, J. R. (1970). Spirometry, lung volumes and airway resistance in normal children aged 5 to 18 years. British fournal of Diseases of the Chest, 64, 15.

Heimlich, E. M., Strick, L., and Busser, R. J. (1966). An exercise response test in childhood asthma. (Abst.) fournal of Allergy, 37, 103.

Jones, R. H. T., and Jones, R. S. (1966). Ventilatory capacity of young adults with a history of asthma in childhood. British Medical fournal, 2, 976.

Jones, R. S. (1966). Assessment of respiratory function in the asthmatic child. British Medical fournal, 2, 972.

Jones, R. S., Buston, M. H., and Wharton, M. J. (1962). The effect of exercise on ventilatory function in the child with asthma. British fournal of Diseases of the Chest, 56, 78.

Jones, R. S., Wharton, M. J., and Buston, M. H. (1963). The place of physical exercise and bronchodilator drugs in the assessment of the asthmatic child. Archives of Disease in Childhood, 38, 539.

Katz, R. M. (1970). Exercise induced bronchospasm in childhood. Annals of Allergy, 28, 361 .

Katz, R. M., and Whipp, B. J. (1969). Cycloergometer. Fournal of Allergy, 44, 122.

Katz, R. M., Whipp, B. J., Heimlich, E. M., and Wasserman, K. (1971). Exercise-induced bronchospasm, ventilation, and blood gases in asthmatic children. Fournal of Allergy, 47, 148.

König, P., Godfrey, S., and Abrahamov, A. (1972). Exerciseinduced bronchial lability in children with a history of wheezy bronchitis. Archives of Disease in Childhood, 47, 578.

McNeill, R. S., Niarn, J. R., Miller, J. S., and Ingram, C. G. (1966). Exercise-induced asthma. Quarterly fournal of Medicine, 35, 55.

Parker, C. D., Bilbo, R. E., and Read, C. E. (1965). Methacholine aerosol as test for bronchial asthma. Archives of Internal Medicine, 115, 452.

Pierson, W. E., Bierman, C. W., and Stamm, S. J. (1969). Cycloergometer-induced bronchospasm. Fournal of Allergy, 43, 136.

Poppius, H., Muittari, A., Kreus, K. E., Korhonen, O., and Viljanen, A. (1970). Exercise asthma and disodium cromoglycate. British Mudical fournal, 4, 337.

Scadding, J. G. (1966). Patterns of respiratory insufficiency. Lancet, 1, 701.

Silverman, M., Connolly, N. M., Balfour-Lynn, L., and Godfrey, S. (1972). Long-term trial of disodium cromoglycate and isoprenaline in children with asthma. British Medical fournal, 3, 378.

Sly, R. M. (1970). Evaluation of disodium cromoglycate in asthmatic children. Annals of Allergy, 28, 299.

Sly, R. M., Heimlich, E. M., Busser, R. J., and Strick, L. (1967). Exercise-induced bronchospasm: effect of adrenergic or cholinergic blockade. Fournal of Allergy, 40, 93.

Williams, H., and McNicol, K. N. (1969). Prevalence, natural history, and relationship of wheezy bronchitis and asthma in children. An epidemiological study. British Medical fournal, 4, 321.

Correspondence to Dr. M. Silverman, Department of Paediatrics, Institute of Diseases of the Chest, London SW3. 